\title{
CORRESPONDENCE.
}

\section{SUGGESTIONS FOR A BETTER MEANS OF MAKING PROVISION FOR THE WIVES AND FAMILIES OF PERSONS ENGAGED IN THE BUSINESS OF LIFE ASSURANCE.}

\author{
To the Editor of the Assurance Magazine.
}

SIR,-As the accredited organ of the assurance interest, I feel sure that you will open the pages of your Magazine, and also lend the aid of your own pen, to call the attention of the directors of Assurance Companies to a question of no mean importance to those in their employment. I refer to the question of allowing to those engaged in the business of life assurance the same advantage as is enjoyed, I believe, by persons engaged in all kinds of trades-I mean, that of obtaining the article dealt in by their employers at the cost price.

My attention has been more particularly called to this subject lately (though it has always been one the equity of which I have never questioned, and one which I have thought a good deal abont) by reading the last report of the National Provincial Bank of England, the Twenty-first Annual Report, and from which I extract the following :-

"It will be in the recollection of the proprietors that, on the occasion of their last annual meeting, it was intimated that a strong desire had been expressed among the officers of the Company for the formation of a Provident Society for their mutual benefit-embracing also, if possible, the principle of a guarantee fund. The precise nature of the scheme it was then left for the directors to consider and determine. At the ontset of their deliberations the directors found that the guarantee scheme was objected to by a large number of the officers, and it was therefore abandoned.

"The other objects aimed at are-First, a provision for the widows and children of officers at their death; and, secondly, a superannuation allowance for the officers themselves.

"To effect the first and most pressing of these objects, the directors recommended to the proprietors that the officers and clerks should be assisted in effecting insurances upon their lives to the following extent, by the Bank paying for them one half of the yearly premium-viz. :

"1st. Managers of branches and agencies to insure for not less than

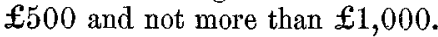

" 2 nd. Junior officers and clerks to take ont policies for sums not under

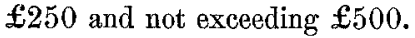

"With respect to the question as to a superannuation allowance, the directors intend to postpone the consideration of it, in the bope that at a future period they will be able to deal with it in a more satisfactory manner than they could do at the present moment. 
"In recommending the above measure for the adoption of the proprietors, the directors feel satisfied that they are consulting the welfare of the establishment, and that any expense which it will entail will be more than compensated by attaching to the Bank experienced and well tried officers, and by the increased devotion to its interests on their part which such consideration for their personal comfort cannot fail to inspire.

"The guarantee project having, as already stated, been abandoned, the $£ 5,000$ voted by the proprietors last year for the benefit of the officers and clerks of the establishment, as a mark of appreciation of their past zealous and faithful services, the directors, acting upon a suggestion thrown out at the last meeting, propose to divide amongst them as a bonus, of which they hope the meeting will approve."

It must be conceded, that the payment of 50 per cent. of the premiums for life assurance, within the limits prescribed, and of course under certain necessary regulations, is a great boon to those in the employment of the Bank, and an act of the greatest liberality on their part.

The General Post Office, too, I am happy to see, have recently agreed to allow certain funds arising from void money orders and from unclaimed property found in dead letters to be applied to a purpose similar to the above-to the extent, however, of the payment of 20 per cent. only of the premiums for life assurance, within certain limits, and similarly, of course, under certain regulations.

I extract the following from a circular issued by command of the Postmaster General to all the officers of the Post Office, and bearing date June, 1854.

"In order to encourage the officers of the Department to make provision for their families at their death by insuring their own lives, the Lords of the Treasury have consented to give assistance in the payment of the premiums on such insurances, and have appropriated to this object a fund arising from void money orders and from unclaimed property found in dead letters.

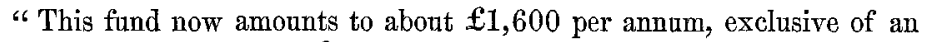
accumulated sum of about $£ 15,000$, which also, by their Lordships' direction, will, with the future interest thereon, be applied to the same purpose. . .

.... "It is intended, if the number of officers who may effect insurances be not too great, that one fifth part of each officer's premium shall be paid by the Department; provided, however, that no officer shall have aid in his payments for more than $£ 300$ of insurance. . . . . .

... . "In all circumstances the Postmaster General will have full power, if at any time he think fit, to withhold the pecuniary assistance contemplated, either in part or altogether. ......

.... "The plan will extend to every Post Office officer in the United Kingdom.

"An existing life insurance in either of the Offices enumerated will entitle the insured to the payment, by the Department, of a portion of his premium equally with a new insurance. ......

.... “The Department's contributions will not extend to premiums greater than annual premiums. Thus if an officer engages to make a single payment only, or a limited number of payments, the contribution from the Department will apply only to such sum as he would have had to pay if his premium had been continuous and annual.

"On quitting the service, an officer will of course cease to receive 
assistance in the payment of his premiums, and to partake of any other advantage of the plan."

It is not my intention to enter upon any criticism of the regulations under which the respective advantages above referred to are to be enjoyed. There are one or two points of detail (I am now referring more particularly to the Bank) the objections to which would readily strike any of your readers that are versed in life assurance business; but I doubt not that those slight imperfections have only to be pointed out to be corrected. As, however, some alterations in the regulations are undoubtedly necessary, I shall refrain from quoting them; but I forward for your own private inspection a copy of the regulations issued by the Bank, with a few marginal comments upon them.

The plan of public Companies assisting those in their employment in so desirable an object as life assurance is so highly to be commended, that I am astonished to find that no such boon is at all general; nor have I been able to ascertain, upon inquiry, that any such advantage is held ont to those employed even in Assurance Companies, where it would be reasonable to suppose such a scheme should have originated, with the single honourable exception of the Albion Life Office, which allows, if I am rightly informed, a reduction of 33 per cent. upon the premiums paid by those in the Company's employment. Some Assurance Companies, I believe, object to allow even the usual commission of 5 per cent. upon the premiums to those in their service.

Now, Sir, it seems to me (and I should feel proud to find that you were of the same opinion) that it is a most reasonable thing for those employed in an Assurance Company to obtain their assurances at the net premium, at least. To grant such an advantage would only be to place those engaged in Assurance Companies upon a similar footing with those employed in all other descriptions of business.

I feel sure that the attention of the directors of Life Assurance Companies, which are almost invariably conducted in a spirit of the bighest liberality, only requires to be drawn to this question to induce them at once to agree to some considerable reduction of the usual preminms on assurances upon the lives of their employés.

The benefits conferred by a scheme of this kind would be greater than almost any other that could be devised. It would tend to encourage habits of forethought and prudence in their servants, which would redound in man'y ways to the advantage of the Company, besides the relief it would afford of freedom from claims being made upon their funds, in consequence of the death of any of their servants, by those dependent upon them for support.

It would, of course, be quite out of place in this Magazine to enter upon any arguments in favour of life assurance. There can be, however, no doubt that the practice is not nearly so general as it should be, not only among the public at large, but even among those who ought to be the first to set the example, the servants and agents of Life Assurance Companies. Strange to say, this is one of those curious anomalies one sometimes meets with; and as that close observer of human nature, Charles Dickens, has pointed out that proctors, as a class, frequently die intestate, so those engaged in life assurance business not unfrequently fail to avail themselves of its advantages.

It has, I understand, been proposed to establish an Office for the 
express purpose of assuring the lives of those engaged in the business. This, it appears to me, is not only perfectly unnecessary, but indeed quite undesirable. A person engaged in a Life Office can effect his policy in his own Office with the least possible tronble to himself and inconvenience to his employers, in the first place; and in the second, many cases may arise in which an Assurance Company might be disposed to assure the life of one of their servants which another Company might decline altogether. I am now supposing the existence of a slight defect in the life proposed, which might be really unimportant; and the Company in whose daily service he was engaged, and whose officers were in the daily habit of seeing him, would be, it is quite clear, much better judges of the case than any other Company conld possibly be.

I am not now entering upon the discussion of the question as to whether the Companies should go so far as to assure the lives of all their employés, whether first class lives or not, though I think that this is a question far from unimportant, and one in favour of which a good deal might be said.

Should this matter be taken up at all, it will then be quite time to inquire how far it might be desirable and proper to admit such lives to the incalculable benefits of life assurance--(benefits far greater, in their unhappy case, than in any other). Of course, a person in radically bad health would not be fit for his duty, and his case would come under another category; and though, of course, organic disease might be latent when he obtained his appointment, or might supervene thereafter, this would probably not be a case of so frequent occurrence as to make it necessary to legislate particularly for it. I should have quite sufficient confidence in the board of directors of a Company of repute, to trust to their taking a fair and liberal view of any case that might come specially before them.

Now it seems to me that no complicated arrangements for carrying out such a scheme as I have advocated are at all necessary. Let the directors of Assurance Companies merely agree to allow as a commission, to those in their service, a deduction from their premiums of assurance of-say, 25 per cent. (which would probably, upon an average, reduce the tabular premium of the several Companies to the net premitum), as long as the life assured remains in their service, to revert to the usual commission of 5 per cent. should he, from any cause whatever, leave the service of the Company, and the thing is done.

If the life assured retire from the Office from ill health, or, after length of service, upon a pension, it would of course be discretionary with the directors to continue to him the previous allowance, or to deal specially with the case according to the estimation in which his services were held, and in proportion probably to his pecuniary means.

If such a boon as this were conceded, I think-

1st, That the assurance of the lives of all the Company's servants, whether married or single, should be made compulsory, for sums proportionate to their respective salaries.

$2 \mathrm{nd}$, That the power of deducting from the salaries the total amounts of the annual premiums, by equal quarterly instalments, less the commission agreed to be allowed, should be reserved to the directors.

3rd, That no assignment or dealing with the policies should be allowed without the permission of the directors, to be specially obtained in each case: to prevent which, I would place a special indorsement upon every poliey issued to the Company's servants. 
4th, That as, upon the institution of any plan of this nature, many of the more prudent of the Company's employés would probably be already assured, and some of them with other Offices than their own (and it would be more likely to be so in the case of prudent and intelligent men, who would in many cases have passed from an inferior position in one Office to a superior appointment in another), a similar allowance of 25 per cent., or whatever amount might be agreed upon, on the premiums actually payable, should be allowed under similar regulations, provided of course the Company so making the allowance should express themselves satisfied as to the respectability and solvency of the Company with whom the existing assurance had been effected.

I do not pretend to have entered into all the details necessary to perfect a plan of this nature, in the first place because this is hardly the time for doing more than what the lawyers call ventilating the case; and, secondly, because the necessary precautions to be taken and steps to be adopted would necessarily occur to every habitual reader of your Magazine - a magazine, Sir, if I may be allowed to express an opinion, which has already done much to promote the theory of life assurance and its cognate subjects, and which I trust will now assist in the good cause of advocating the practice of life assurance, as applied to those engaged in daily assisting to carry its blessings into the families of thousands.

You will see that there are many points that $I$ have not touched upon; not because I have been unmindful of them, but because I am fearful of intruding too much upon your space-as for instance, whether similar allowances should not be made, as respects the insurance from fire, to those engaged in Fire as well as Life Companies. I have not proposed an allowance to the extent of 50 per cent., as agreed to be made by the National Provincial Bank of England. Of course, such Assurance Companies as were in a position to make such an allowance might do so; but I feel that many Assurance Companies are hardly in so prosperous a condition as the Bank in question, and that this accordingly could hardly be expected.

A scheme of this kind should be made as universal as possible, for many reasons: one I will name, which is, that if the same plan be agreed to by all the respectable Companies, a person leaving one Company and entering into the service of another would still obtain an equal amount of allowance, and would know what he had to expect when he effected his assurance in the first instance. I feel sure that no boon that could be granted by the directors of Companies to those in their employ would be of more real advantage than the one proposed. It could be granted at a very small sacrifice of profits, and I should hope that the advocacy of your able pen would bring about its almost universal fulfilment.

I have the honour to be, \&c.,

Alliance Life Office, 1 st August, 1854.

WM. PORTER.

Note.-The subject referred to in this communication is of such obvious interest and importance to the profession, and Mr. Porter's observations upon it are so much to the purpose, that, for the present at least, we feel it quite unnecessary to do more than submit his letter to our readers, not doubting that it will attract the notice and secure the consideration it so well deserves.-Ev. $A$. $M$. 